\title{
Land subsidence, seismicity and pore pressure monitoring: the new requirements for the future development of oil and gas fields in Italy
}

\author{
P. Macini ${ }^{1}$, E. Mesini ${ }^{1}$, L. Panei ${ }^{2}$, and F. Terlizzese ${ }^{2}$ \\ ${ }^{1}$ University of Bologna, School of Engineering and Architecture, Bologna, Italy \\ ${ }^{2}$ Italian Ministry for Economic Development, Rome, Italy \\ Correspondence to: P. Macini (paolo.macini@unibo.it)
}

Published: 12 November 2015

\begin{abstract}
The Emilia earthquake of 2012 (Italy) stimulated a controversial debate concerning the possibility that the event could have been induced or triggered by underground fluids production. The public discussion led the Italian Government to issue a protocol of guidelines for the monitoring of microseismic activity, ground deformation and reservoir pore pressure. The guidelines will be put into operation as soon as practicable when licensing is being considered, and all data provided by mining operators must be made available to the relevant Authorities. The implementation of an outreach and communication program to local residents and administrative authorities is prescribed, so that the civil and scientific community at large can gain confidence that operations are being managed optimally.
\end{abstract}

\section{Introduction}

After the well-known "Emilia" seismic sequence of May 2012 (Pizzi and Scisciani, 2012), located in the densely populated Emilia-Romagna Region (Italy), causing 27 casualties and relevant damages to buildings and industrial infrastructures, doubts have been raised on the possibility that the above seismic sequence could have been induced or triggered by underground fluids production or injection.

The area under investigation (and more extensively the whole Po Plain area) is well known for the large number of oil and gas fields, discovered since the early 1950's. These fields significantly boosted the Italian industrial reconstruction after World War II and the area was intensely explored until the late 1980's. Today, hydrocarbon exploration and production in this area is in its final stage. The Po plain is a mature petroleum province and it is becoming increasingly marginal, not the least because of the strong environmental limitations and the low social acceptability of management practices and conditions in the field of fossil fuels.

In particular, near the measured epicenters of the two main shocks (in the order of several tens of $\mathrm{km}$ ) there are some oil and gas fields, an underground gas storage inside a de- pleted gas field and a closed-loop water-dominated mediumtemperature geothermal field.

In the view of the above, the Italian Department of Civil Protection, following the request of the Government of Emilia-Romagna Region, appointed an independent International Commission for evaluating the possible relationships between hydrocarbon exploration and production and a marked increase of seismicity in the area hit by the May 2012 earthquakes. In particular, the Commission, named ICHESE (International Commission on Hydrocarbon Exploration and Seismicity in the Emilia region) reviewed and evaluated all available geological, geophysical and fluid production information in order to assess the likelihood of the above concerns. In particular, the final report (ICHESE, 2015), issued in April 2014, focused on three active production sites, located close to the epicenters of the seismic sequence: the geothermal field (Casaglia, geothermal production lease "Ferrara"), the underground gas storage field (Minerbio, gas storage lease "Minerbio Stoccaggio") and an oilfield in its final stage of production (Cavone, hydrocarbon production lease "Mirandola").

ICHESE report concluded: "it is highly unlikely that the activities of hydrocarbon exploitation and the geothermal ac- 
tivity have produced sufficient stress change to generate an "induced" seismic event. While it cannot constitute proof, the current state of knowledge and all the processed and interpreted information does not allow the ruling out of the possibility that the actions involved in hydrocarbon exploitation in the oilfield may have contributed to "trigger" the Emilia seismic activity" (author's italics). ICHESE report eventually suggests some recommendations to investigate the issue in more details. Amongst these, we recall the following: implementation of a coupled hydro-mechanical model of the area and monitoring of seismic activity, ground deformation and pore pressure. ICHESE report originated a sharp debate in the media, mining operators, regulating and administrative authorities, local residents and the scientific community. The oil and gas industry reacted very responsibly, granting a positive and transparent cooperation with the Authority responsible for the control (the Dept. of Energy and Mineral Resources of the Italian Ministry for Economic Development), the Regional Government, the scientific community and the public at large.

In particular, the Italian oil and gas industry (the supposedly guilty party indicated by the ICHESE report) reacted immediately, by promoting a collaboration agreement between the Ministry for Economic Development (MISE), the Emilia-Romagna Regional Government and the oil company "Società Padana Energia" (owner of the Mirandola lease and of Cavone oil plant), together with Assomineraria (the Italian Petroleum and Mining Industry Association). The aim of the project was the immediate development of monitoring and research at the "Cavone" oilfield, in order to provide a complete answer on the questions remained open and unresolved in the ICHESE report. The project is known as "Cavone Laboratory", whose activities are detailed in the last chapter of this paper. The results of the activities, still ongoing, are continuously updated and available online at http://labcavone.it/ and http://www.assominerariacavone.org/. Transparency and accountability characterize these activities. Cavone Laboratory fully reflects these principles and on request make public the entire database of monitoring and modeling of the reservoir. Historical data and recent ones are available to the academic world, students and scholars who wish to analyze them.

In parallel, an updated, complete and extensive analysis of geological and geophysical data (together with the construction of a novel geomechanical model) of the Cavone reservoir and surrounding formations has been prepared (Astiz et al., 2015; Jha et al., 2014). The first step of the above activities concluded: "there is no physical reason to suspect that pressure changes at the hypocenters associated with production or injection activities at Cavone oilfield triggered the seismic sequence of May 2012". The above project produced also an updated fully coupled hydro-mechanical model of the Cavone reservoir, as recommended by the ICHESE report.

In the same period, another study was published by the Italian National Institute for the Environmental Protection and Research (ISPRA, 2015), concerning the possible relationship between induced/triggered seismicity and anthropogenic activities in Italy.

Notwithstanding all the above, ICHESE's conclusions and recommendations prompted MISE to issue (MISE, 2015) a protocol of guidelines for the monitoring of land subsidence, pore pressure and seismic activity. In particular, existing and future hydrocarbon and geothermal activities must be supported by high technology monitoring networks aimed to study the time evolution of the three essential aspects: microseismic activity, ground deformation and pore pressure. These should be put into operation as soon as practicable when licensing is being considered. Finally, it is necessary that all the relevant data provided by mining operators are made available to the authorities responsible for the control. It is critically important to implement also an outreach and communication program to local residents and administrative authorities, so that the civil and scientific community at large can gain confidence that operations are being managed optimally.

This paper details and illustrates the above guidelines, and analyzes the preliminary results of experimental monitoring activities performed at selected pilot test sites.

\section{The new rules of the game}

The abovementioned document (MISE, 2015) is a first formulation of the technical "Guidelines" for the implementation, management and control of the monitoring, as well as the decision-making methods in case of possible changes of the monitored parameters. These guidelines will be firstly tested on some pilot sites, chosen among the onshore leases that operate the injection of the produced water and selected underground gas storage leases (in most of which, both seismic and ground deformations monitoring networks are already in operation). The monitoring results will be published and shared with MISE and the Government of the Regions concerned with such activities. It is hoped that that this document will be re-evaluated after two years, on the following basis:

- the experience gained in the pilot sites representing different case studies concerning, among the other, carbonatic reservoirs that include injection activities;

- a feasibility study, including construction and operative costs.

The Guidelines aim to establish procedures and monitoring protocols including methods for the analysis of spatial and temporal parameters related to seismicity, ground deformation and pore pressure. In particular, seismic monitoring is addressed to identify and locate the seismicity in a control volume surrounding the anthropic activities, also with the aim of eventually distinguishing the natural seismicity from the one possibly caused by such activities. Monitoring should 
allow to track the evolution of seismicity in space, time and magnitude in order, if necessary, to modify or, under certain circumstances, to halt the activities. Ground deformation monitoring aims to identify possible surface deformation (related to the anthropic activities) and to study its spatial and temporal evolution. Pore pressure monitoring is addressed to estimate reservoir pressure through downhole measurements, possibly also with the support of interference test with neighboring wells, in order to validate the hydrodynamic model of the reservoir and to evaluate potential pressure variations in space and time.

In general, these Guidelines (after an appropriate revision) might also be adopted in the future for industrial activities such as dam construction, geothermal fluids production (conventional and closed-loop), enhanced geothermal systems (at present not performed in Italy), $\mathrm{CO}_{2}$ geological storage (at present not performed in Italy), underground mining and tunneling.

The Guidelines recommends that the new monitoring infrastructures are designed also taking into account the principle of "upgrading the existing" and, therefore, to provide, after due evaluation, a possible improvement of infrastructures already operating to obtain the required performances.

Aside from the specifications of the monitoring network (see below), it is recommended that the mining operators prepare and make available, even in the light of geological and seismotectonic studies previously carried out, the following data and information, useful for the design of monitoring networks:

a. detailed geological cross sections (three at least);

b. seismic profiles (possibly in 3-D);

c. 3-D stratigraphic-structural model;

d. estimation (log or cores) of primary and secondary porosity along a reference well profile;

e. evaluation of rock compaction and of expected subsidence;

f. simulation of fluid migration nearby the reservoir;

g. location of active faults adjacent (within $3 \mathrm{~km}$ ) or neighboring (within $15 \mathrm{~km}$ ) to the reservoir;

h. general kinematic framework of the area;

i. evaluation of lithostatic stress changes;

j. evaluation of the possible volume around an injection well through which the injected fluids can migrate, and planning of the monitoring actions;

k. implementation of a geomechanical model, and its periodical updating.
It is also recommended to construct surface piezometric wells (possibly equipped with an extensometer), and to perform geoelectric or magnetotelluric surveys in order to assess resistivity anomalies and possible variation in time.

\section{Seismic monitoring}

The Guidelines firstly specify the geometrical definition of two distinct control volumes (referred as "internal" and "extended" control volume), i.e. the size of subsoil potentially interested by specific anthropic activities.

The internal control volume circumscribes the area of the activities on a local scale, but it must be wide enough to include the phenomena of induced seismicity. In this control volume, the seismic monitoring network must have the maximum sensitivity, to allow the use of the most advanced techniques for the localization of earthquakes and the reconstruction of seismic velocity models and, if data are adequate, to track the possible migration of seismicity. The seismic monitoring network must strictly comply with the following requirements:

- in the internal control volume, detect and locate earthquakes in the range of local Magnitude $\left(M_{\mathrm{L}}\right)$ in between 0 and $1\left(0 \leq M_{\mathrm{L}} \leq 1\right)$ and with uncertainty in locating the hypocenter of some hundreds of meters;

- in the extended control volume, improve of about 1 unit the level of the magnitude of completeness of records kept by the National or Regional seismic monitoring networks implemented for purposes of civil protection at National or Regional level (the monitoring network must be able to locate the hypocenter with an uncertainty of about $1 \mathrm{~km}$ );

- Determine the acceleration and velocity of ground motion caused by any earthquake at the measurement point;

- Integrate accurately with the existing monitoring networks (National, Regional and Local) in order to improve the accuracy and completeness of the measurements.

Concerning the timing, it is recommended that the seismic monitoring will have to start at least one year before the start of production (or storage) operations, in order to verify and measure the natural background in "undisturbed" conditions; it will operate along all the production stage and continue for at least one year after the conclusion of the activities.

\section{Ground deformation monitoring}

The Guidelines recommend that the monitoring must cover the surface area corresponding to internal and extended control volume, complying with the following requirements: 
- it must provide a detailed deformations framework, estimated by means of Earth observation satellite, i.e. interferometric (InSAR) measurements performed during the past 15 to 20 years (minimum during the last 10 years). The accuracy must be of the order of 5 to $10 \mathrm{~mm}$ (for InSAR LOS measurements) and about 1 to $2 \mathrm{~mm} \mathrm{yr}^{-1}$ for the estimates of deformation rates.

- the above framework must be updated by InSAR measurements repeated 1 to 4 times a year and must continue for at least three years after the conclusion of production (or storage) operations.

- the deformation obtained by InSAR must be integrated and complemented with additional measurements acquired by a continuous GPS network.

- the Controller should evaluate the opportunity to integrate InSAR and GPS information with precision spirit leveling measurements. The precision spirit leveling must be carried out every 2 or 3 years.

The complete results of the ground deformation measurements will be described and analyzed in dedicated reports, to be published indicatively every 3 to 12 months (recommended: 6 months).

\section{Pore pressure monitoring}

The Guidelines suggest performing pore pressure monitoring only for future field activities. Concerning the ongoing activities, the monitoring should be implemented only in the cases in which the existing wells can be fitted with the equipment to perform this measurement. The same holds also for interference test, which will be performed only if a suitable set of neighboring wells already exists.

As far as new storage or injection wells are concerned (excluding the production wells), pore pressure (or reservoir pressure) will be measured by downhole tools ("surface readout") inserted in the well completion, which provide a continuous measurement in real time. In some existing wells, it is possible to use "memory gauges" temporarily run at the bottom of the well by a wireline unit. Memory gauges allow the pressure measurement (not in real time) for a limited time (a few weeks): in fact, data are stored in an internal digital memory and downloaded only when the tool is retrieved at the surface.

Periodic static pressure profile will be carried out on specific wells of the field. Pore pressure in the volume of rock surrounding the monitored wells, which however is difficult to measure and highly uncertain, can be estimated by performing correlations with other monitoring wells, also through the application of mathematical models. The results of pore pressure measurements will be described and analyzed in dedicated reports, to be published indicatively twice a year.

\section{The responsible of the monitoring, data analysis and publication}

Today in Italy there is not a structure with specific expertise to monitor and identify possible effects of seismicity induced by human activities. Therefore, it is necessary to identify a third-party highly qualified technical-scientific subject (the Responsible of the Monitoring, RM) to support the Control Authority (MISE) in the management, analysis and use of monitoring data. The RM will be chosen among of one or more Universities or Research Institutions of proven expertise, possibly in consortium, or even with private structures. The Operator, with the advice of the RM, designs and constructs the monitoring networks (i.e. purchase, install or modify the existing equipment, and is responsible for their maintenance and management). The RM examine and evaluate the monitoring project (that must be finally approved by MISE), and performs data processing, analysis and interpretation.

An important aspect concerns the analysis and the procedures to steer the actions to be taken on the basis of the results of the monitoring. The working group that drafted the Guidelines concluded that in Italy today there are not proven methods of physical or statistical analysis that allow correlating induced seismicity within a maximum of one or two days, a reasonable interval needed to take decisions through applicable procedures. For this reason, it was chosen a "traffic light" approach based on parameters measured only within a limited control volume around the well and specific ground deformation measurements.

It is proposed to adopt, on an experimental basis, a decision-making system defined through four levels of activation, based on the assessment of the geodynamic model of the area and the overall framework of a series of parameters monitored in the control volume, including:

- variation of the number, frequency, magnitude and spatial distribution of seismic events;

- peak values of acceleration and ground motion speed;

- change of ground deformation rates;

- variation of pore pressure.

The four levels of activation are the following: (a) ordinary (green), (b) attention (yellow), (c) reduction of field activities (orange), (d) interruption of field activities (red).

This traffic light system provides procedures for taking actions associated with different activation levels, based on threshold values of the monitored parameters. At present, it seems not appropriate to adopt a decision model with automatic actions linked to precise threshold values. In fact, given the variability of the geological contexts, the depth and the technologies used for fluid production operations, the natural background seismicity and its depth, in general it is not possible to determine these threshold values uniquely. 
Therefore, the decision-making system establishes the transition from one level to the other via a combined evaluation of RM, MISE, Regional Government and Operator, each one within their respective responsibilities. This must be undertaken as soon as originates a framework of monitored parameters "out of the ordinary", and the recognition of a possible correlation between the abovementioned changes and the ongoing field activities is detected.

The guidelines prescribes to adopt a traffic-light system with automatic actions (i.e. linked to precise threshold values) exclusively for the activities involving the injection of produced fluids (Table 1). For any transition from one level to the other is sufficient that one of the parameters (measured in the internal control volume) exceed the indicated threshold.

In order to ensure the effectiveness and transparency of the activities, it is planned the construction of a dedicated website of the MISE, with a special area containing specific sections for individual fields and leases, dedicated to the dissemination of information on existing and ongoing activities and data acquired during the monitoring.

\section{Cavone monitoring laboratory}

The Cavone Monitoring Laboratory originated from an "Agreement" between MISE Ministry, Emilia-Romagna Regional Government, oil company "Società Padana Energia", and Assomineraria to set up a pioneering center for research, monitoring and dissemination of local data. Having obtained the opinion of the Local Government Bodies, the Ministry and the Emilia-Romagna Regional Government asked the Società Padana Energia to make the Cavone oilfield available for a 90-day time period, in order to perform monitoring and research activities in line with the recommendations set forth in the ICHESE report. The operations carried out were the following: (a) updating of the static and dynamic models of the Cavone reservoir; (b) planning of interference and injectivity tests at selected wells; (c) assessing feasibility of further monitoring for the first-time application of the Guidelines. The results of these operations were made available, with all due transparency and dissemination, by a dedicated information point, set up at the Cavone site, and through the website http://www.labcavone.it. After the 90-day period, all the parties met to evaluate the outcomes of the operations and to plan any further action to be taken.

The Cavone Laboratory project started on 18 April 2014, when the Work Group began to define the details and started the operations as set down in the abovementioned Agreement. At the same time, the local information point was set up, where the results of operations were updated daily. On 16 May 2014, the labcavone website was published. The website was designed to inform local communities and the community at large of the contents and daily progress in the study and monitoring phases, and has remained active af-
Table 1. Threshold values of seismic parameters measured in the internal control volume utilized to establish the levels of activation: Maximum Magnitude $\left(M_{\max }\right)$, Peak Ground Acceleration (PGA), Peak Ground Velocity (PGV). For any transition from one level to the other is sufficient that one of these parameters exceed the indicated threshold.

\begin{tabular}{lllcc}
\hline $\begin{array}{l}\text { Activation } \\
\text { level }\end{array}$ & $\begin{array}{l}\text { Traffic- } \\
\text { light }\end{array}$ & $M_{\max }$ & $\begin{array}{c}\text { PGA } \\
(\% \mathrm{~g})\end{array}$ & $\begin{array}{c}\mathrm{PGV} \\
\left(\mathrm{cm} \mathrm{s}^{-2}\right)\end{array}$ \\
\hline 0 & Green & $M_{\max } \leq 1.5$ & - & - \\
1 & Yellow & $1.5<M_{\max } \leq 2.2$ & 0.5 & 0.4 \\
2 & Orange & $2.2<M_{\max } \leq 3.0$ & 2.4 & 1.9 \\
3 & Red & $M_{\max }>3.0$ & 6.7 & 5.8 \\
\hline
\end{tabular}

ter the conclusion of the Laboratory program, as a service provided to the community. By means of data provided by the Italian National Institute of Geophysics and Volcanology (INGV) and by local monitoring stations, it displays, within $24 \mathrm{~h}$, the data relating to the seismicity of the entire lowland area of the Province of Modena and to a larger area of approximately $81000 \mathrm{~km}^{2}$. The website has a section dedicated to the answers to frequently asked questions, in order to make the relevant topics as clear as possible.

From 16 May to 16 June 2014, the field activity program was carried out, with the aim of collecting data. After its completion, approximately one million pressure and temperature values had been recorded, together with 5000 flow rate measurements. The advanced studies carried out during the 90 days of activity of the Laboratory led to identify the oilfield of Cavone as the first Italian testing site for the application of the Guidelines prepared by MISE. At present, based on a further agreement for the first application of the Guidelines in Italy (23 July 2014), at Cavone oilfield, study and research are still under way, aimed to the field implementation of the three main monitoring areas: seismic, pore pressure and ground deformation monitoring.

As of today (May 2015), the Cavone microseismic network consists of four stations, whose task is to record and localize the local seismicity within a range and depth of $10 \mathrm{~km}$ of the next station. This local network is linked to the Italian National seismic network, a complex structure including over 300 monitoring points. The large majority of these stations was installed and are managed by INGV, though the Italian National Earthquake Center, but a significant number of seismometers were installed and are maintained by other INGV Departments (Naples, Catania, Milan) or by other Italian or European research institutions.

Pore pressure monitoring is performed by means of specific instruments (memory gauges), which record pressure and temperature, temporarily located at the bottom of one or more existing wells. Periodical campaigns are carried out for the measurement of the static pressure of the field. The average pressure value in the volume surrounding the wells 
is estimated by correlation with other monitoring wells and by mathematical models.

Ground deformation monitoring, so far based on InSAR interferometry only, was tested at the Cavone oilfield. The Canadian satellite RADARSAT-1 recorded images of the concerned areas from 20 to 29 May 2012 (the "Emilia" seismic sequence of May 2012) and, based on such images, it was reconstructed an accurate map of the ground deformation induced by the abovementioned earthquake.

\section{Conclusions}

The Guidelines (MISE, 2015) are the first Italian document collecting technical specifications of monitoring networks, decision-making framework and related procedures in the field of underground fluid production and storage activities. The document highlights some elements for which there is a lack of operative experience; therefore, it points out that the Guidelines should be re-evaluated, according to direct experience, approximately two years after its first experimental application on pilot test sites.

One of the main concern is hydrocarbon production involving the injection of formation fluids. In order to minimize the potential impact, for these activities is recommended to preserve the original natural stress (maintaining the balance of fluids extracted and injected as close to zero as possible) and to keep the pressure of the injection as close as possible to the initial (natural) pressure.

One of the most analyzed point was the general organizational structure, for which it is necessary to assign the designing of the monitoring networks (together with data analysis and interpretation) to third-party public or private research agencies, the Responsible of the Monitoring (RM). These are controlled by the Ministry itself, in order to separate the Operator and the RM, to ensure the independence of scientific assessments and, finally, to establish a proper level of control over the monitoring.

Another issue raised was that of the definition of the areas to be monitored and how to implement effective decisionmaking procedures. Especially for the seismic monitoring, it was necessary to consider and synthesize the experiences derived from different productive activities. The unifying principle has been identified in the definition of two volumes, respectively "internal" and "extended" control volume based on the positions of the wells and the extent of the reservoir.

The last point is that concerning the decisions to be taken depending on the results of monitoring. It was chosen an approach based on four levels of activation. It was suggested the adoption, on an experimental basis, a strict traffic light system only for the fields involving injection activities. The traffic light was defined by threshold values based on magnitude, ground velocity and acceleration measured within the internal control volume. Aware of the inherent difficulties in the implementation of the system, it is believed that these
Guidelines will have greater applicability in the future, when knowledge and scientific methodologies will be further established, capable of providing immediate and reliable answers.

\section{References}

Astiz, L., Dieterich, J. H., Frohlic, C., Hager, B. H., Juanes, R., and Shaw, J. H.: On the Potential for Induced Seismicity at the Cavone Oilfield: Analysis of Geological and Geophysical Data, and Geomechanical Modeling. Study prepared for the Italian Petroleum and Mining Industry Association, Assomineraria, 2014, http://www.assominerariacavone.org/uploads/tappe_ lavori/11/attachment/cavonereportfinal_v03.pdf, last access: April 2015.

ICHESE - International Commission on Hydrocarbon Exploration and Seismicity in the Emilia Region: Report on the Hydrocarbon Exploration and Seismicity in Emilia Region, February 2014, http://geo.regione.emilia-romagna.it/ gstatico/documenti/ICHESE/ICHESE_Report.pdf, with appendices: http://geo.regione.emilia-romagna.it/gstatico/documenti/ ICHESE/Appendices.pdf, last access: April 2015.

ISPRA - National Institute for the Environmental Protection and Research: Possible relationship between induced/triggered seismicity and anthropogenic activities in Italy (Rapporto sullo stato delle conoscenze riguardo alle possibili relazioni tra attività antropiche e sismicità indotta/innescata in Italia, Jun. 27, 2014, in Italian), http://www.isprambiente.gov.it/files/notizie-ispra/ notizia-2014/rapporto-sismicita-indotta-innescata-in-italia/ Rapporto_sismicitaindottainnescata_initalia.pdf, last access: April 2015.

Jha, B., Plesch, A., Shaw, J. H., Hager, B. H., and Juanes, R.: Coupled Flow and Geomechanical Modeling of Fluid Production and Injection in the Cavone Oil Field, Northern Italy: an Assessment of the Potential for Induced Seismicity, AGU Fall Meeting, 1519 December 2014, San Francisco, CA, 2014.

MISE - Italian Ministry for Economic Development: Oilfield Monitoring Guidelines (Indirizzi e linee guida per il monitoraggio della sismicità, delle deformazioni del suolo e delle pressioni di poro nell'ambito delle attività antropiche, Nov. 24, 2014, in Italian), http://unmig.sviluppoeconomico.gov.it/unmig/ agenda/upload/85_238.pdf, last access: April 2015.

Pizzi, A. and Scisciani, V.: The May 2012 Emilia (Italy) earthquakes: preliminary interpretations on the seismogenic source and the origin of the coseismic ground effects, Ann. Geophys., 55, 751-757, 2012,

http://www.ann-geophys.net/55/751/2012/. 